\title{
Immune Correlates of Resistance to Trichinella spiralis Reinfection in Mice
}

\author{
Ki-Back Chu',2, Sang-Soo Kim², Su-Hwa Lee, ${ }^{1,2}$, Dong-Hun Lee ${ }^{1,2}$, Ah-Ra Kim,, Fu-Shi Quan² \\ ${ }^{1}$ Department of Biomedical Science, Graduate School, Kyung Hee University, Seoul 02447, Korea; '2Department of Medical Zoology, Kyung Hee \\ University School of Medicine, Seoul 02447, Korea
}

\begin{abstract}
The immune correlate of host resistance induced by reinfection of Trichinella spiralis remains unclear. In this study, we investigated immune correlates between the resistance and serum lgG antibody level, $\mathrm{CD}_{2} 3^{+} \operatorname{lgM}^{+} \mathrm{B}$ cells, and eosinophil responses induced by $T$. spiralis reinfection. Mice were primarily infected with 10 or 100 T. spiralis larvae (10 TS, 100 TS), respectively, and after 4 weeks, they were challenge infected with 100 T. spiralis larvae (10-100 TS, 100-100 TS). Upon challenge infections, 10-100 TS mice induced significantly higher levels of $T$. spiralis-specific total lgG antibody responses in sera and antibody secreting cell responses in spleens compared to 100-100 TS mice, resulting in significantly reduced worm burdens in 10-100 TS mice (60\% and 70\% reductions for adult and larvae, respectively). Higher levels of eosinophils were found in mice primarily infected with 10 TS compared to those of 100 TS at week 8 upon challenge. $\mathrm{CD}_{23}{ }^{+} \mathrm{IgM}^{+} \mathrm{B}$ cells were found to be increased significantly in mice primarily infected with $10 \mathrm{TS}$. These results indicate that primary infection of 10 larvae of $T$. spiralis, rather than 100 larvae, induces significant resistance against reinfection which closely correlated with $T$. spiralis-specific lgG, eosinophil, and CD23+ $\operatorname{lgM}^{+} \mathrm{B}$ cell responses.
\end{abstract}

Key words: Trichinella spiralis, resistance, lgG, eosinophil, $\mathrm{CD}_{2} 3^{+} \mathrm{B}$ cell, $\operatorname{lgM}{ }^{+} \mathrm{B}$ cell

\section{INTRODUCTION}

Trichinellosis caused by Trichinella spiralis is a globally distributed disease. There have been reports of outbreaks from China, Japan, Thailand, Laos, Vietnam, Korea, Eastern Europe, and West Africa [1,2]. Human infection occurs through ingesting T. spiralis larvae that are encysted in muscle tissue of meat from domestic or wild animals. Although reinfection with $T$. spiralis occurs frequently in domestic and wild animals with occasional human T. spiralis outbreak, the host responses to reinfection with $T$. spiralis remains largely unknown $[1,3,4]$.

Antibody responses against T. spiralis in rats are dose-dependent, showing a positive correlation between infection dose and serum antibody levels [5]. In hosts, such as cattle, sheep, goat, horses, wild boars, pigs, and foxes, antibody responses induced by T. spiralis infections have also been documented to be dose-dependent [6-16]. A study investigating the resistance against reinfection reported the reductions of T. spiralis in the

- Received 23 June 2016, revised 27 September 2016, accepted 29 September 2016. *Corresponding author (fsquan@khu.ac.kr)

(c) 2016, Korean Society for Parasitology and Tropical Medicine

This is an Open Access article distributed under the terms of the Creative Commons Attribution Non-Commercial License (http://creativecommons.org/licenses/by-nc/4.0) which permits unrestricted non-commercial use, distribution, and reproduction in any

medium, provided the original work is properly cited. small intestine and muscle for adults and larvae, respectively. In this study, only a single high dose of T. spiralis larvae (400 larvae per mouse) were used for primary and secondary infections in BALB/c mice [17]. Since humans or animals could be infected more frequently by a low number of larvae in natural conditions [18], the study of host responses induced by different dose of infection, by a low dose of T. spiralis infection in particular, would have an important impact.

A recent study indicates that eosinophils served to limit the number of new born larvae of T. spiralis that migrated in tissue and colonized in skeletal muscles [19]. Eosinophils are required for control of a secondary infection by T. spiralis, and the effect is dependent on the presence of specific antibodies [19]. Thus, it would be of utmost importance to clarify the host resistance to reinfection, including host eosinophil responses with T. spiralis-specific antibody responses. Circulating $\mathrm{CD} 23^{+} \mathrm{B}$ cell subset correlates with the development of resistance to Schistosoma mansoni reinfection [20]. Memory B cells reside in secondary lymphoid organs, where they can rapidly mobilized upon a new antigenic encounter. Memory B cells are composed of 2 subsets, an $\mathrm{IgM}^{+}$and an $\mathrm{IgG}^{+}$subset. The IgG subset comprises of IgG1 cells, which represent the major fraction of antigen-specific switched memory B cells. However, the existence of a long-lived $\mathrm{IgM}^{+}$memory subset, in addition 
to $\mathrm{IgG}^{+}$memory set, was found in a mouse model recently [21]. Thus, a study on $\mathrm{CD}_{2} 3^{+} \mathrm{B}$ cell and $\mathrm{IgM}^{+}$memory subsetrelated resistance against $T$. spiralis infection along with antibody response and eosinophil response would have a significant impact.

\section{MATERIALS AND METHODS}

\section{Animal and parasite}

Female inbred BALB/c (aged 8 weeks; Nara Biotech, Kyonggi-do, Korea) were used. Groups of mice $(\mathrm{n}=10)$ were orally infected with 10 larvae (10 TS) or 100 larvae of T. spiralis (100 TS). The parasites used in this study were from T. spiralis Korea isolate [22] and maintained by serial passage in SD rats. Muscle tissues were collected and muscle stage larvae were isolated by artificial digestion by using pepsin- $\mathrm{HCl}$ at $45 \pm 1^{\circ} \mathrm{C}$.

\section{Primary infection and challenge infection}

Groups of mice $(\mathrm{n}=10)$ received primary infection with $10 \mathrm{TS}$ or 100 TS via an oro-gastric tube. Challenge infections (reinfection) were performed at week 4 after primary infections as indicated in Fig. 1A. At week 8, mice were sacrificed, and the dia-

\section{A}

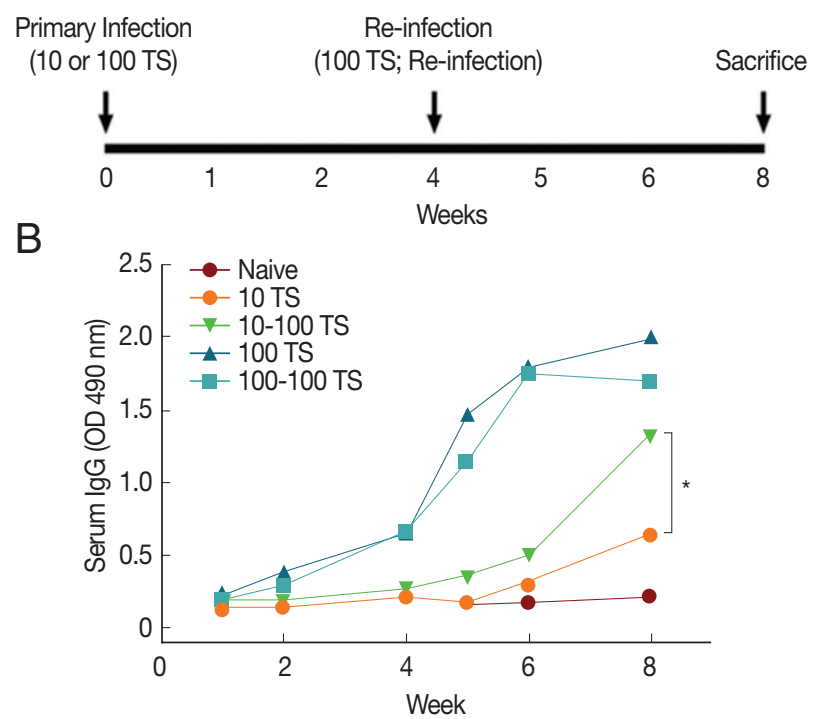

Fig. 1. Experimental schedule and lgG antibody responses. (A) Mice $(n=10)$ were primarily infected with 10 (10 TS) or 100 (100 TS) larvae of $T$. spiralis, and after 4 weeks, mice were challenge infected with 100 larvae of T. spiralis (10-100 TS, 100-100 TS). (B) Antibody responses were determined by ELISA from mice at week 2 and 4 after primary and post-reinfection. A significant difference was found between 10 TS and 10-100 TS $\left({ }^{*} P<0.05\right)$. phragms were collected. The diaphragm from individual mouse was digested with pepsin- $\mathrm{HCl}$ at $37^{\circ} \mathrm{C}$ overnight, and T. spiralis larvae were harvested and counted. All animal experiments and husbandry involved in these studies were conducted under the guidelines of the Kyung Hee University IACUC, Seoul, Korea. Kyung Hee IACUC operates under the National Veterinary Research and Quarantine Service (NVRQS) and regulations of the World Organization for Animal Health (WOAH).

\section{T. spiralis excretory/secretory antigen preparation}

T. spiralis excretory/secretory (ES) product was produced as described previously $[23,24]$. T. spiralis larvae were isolated from mouse muscle tissue by artificial digestion. Clean larvae were incubated in a $\mathrm{CO}_{2}$ incubator for $24 \mathrm{hr}$ at $37^{\circ} \mathrm{C}$ in a petri dish containing RPMI-1640 culture medium without fetal bovine serum (FBS). The culture supernatants were collected by centrifugation. The supernatant was dialyzed and lyophilized. The protein concentration was determined by DC Protein Assay Kit (Bio-Rad, Hercules, California, USA), and T. spiralis ES products were stored at $-70^{\circ} \mathrm{C}$ until use.

\section{Worm burden determination}

Mice were sacrificed at day 7 and week 4 after challenge infection. Intestine from individual mice was collected and cut into $10 \mathrm{~cm}$ long pieces, placed into dish, and incubated in $0.9 \%$ saline at $37^{\circ} \mathrm{C}$ for $2 \mathrm{hr}$. After incubation, intestines were discarded, and the sediment was counted under stereomicroscopy. The mouse diaphragm from individual mouse was collected and digested with pepsin- $\mathrm{HCl}$ at $37^{\circ} \mathrm{C}$ overnight. T. spiralis adults and larvae were harvested and counted under a microscope.

\section{Antibody responses}

Blood samples were collected by retro-orbital plexus puncture at week 1, 2, and 4 after primary infection and at week 1 , 2, and 4 post-challenge infections as indicated in Fig. 1A. T. spiralis-specific serum IgG antibodies were determined by ELISA, as described previously [25]. Briefly, 96-well microtiter plates (Nunc Life Technologies, Basel, Switzerland) were coated with $100 \mu \mathrm{l}$ of ES product at a concentration of $4 \mu \mathrm{g} / \mathrm{ml}$ in coating buffer ( $0.1 \mathrm{M}$ sodium carbonate, $\mathrm{pH} 9.5)$ at $4^{\circ} \mathrm{C}$ overnight. The plates were then incubated with mouse sera (1:100) from infected mice. Horse-radish peroxidase-labeled goat antimouse IgG (1:2,000) (Zymed, San Francisco, California, USA) was placed into plates and incubated at $37^{\circ} \mathrm{C}$ for $1.5 \mathrm{hr}$. Finally, 
the substrate o-phenylenediamine (Zymed) in citrate-phosphate buffer ( $\mathrm{pH}$ 5.0) containing $0.03 \% \mathrm{H}_{2} \mathrm{O}_{2}$ (Sigma) was used for color development. The optical density at $490 \mathrm{~nm}$ was read using an ELISA reader (Molecular Devices, Sunnyvale, California, USA).

\section{Detection of antibody-secreting cells (ASCs) in the spleen}

Freshly isolated spleen cells $\left(1 \times 10^{6}\right.$ cells $)$ were added to a 96-well culture plate and incubated for 3 days at $37^{\circ} \mathrm{C}$ under $5 \% \mathrm{CO}_{2}$ to detect T. spiralis-specific ASCs. ASCs were detected in the supernatant using an ELISA plate coated with T. spiralis ES antigen. Horseradish peroxidase (HRP)-conjugated secondary goat-anti-mouse antibodies were added and incubated. The substrate 0 -phenylenediamine (Zymed) was used as a measure of HRP activity, and optical density was read at $490 \mathrm{~nm}$.

\section{Flow cytometry analysis}

At week 4 post-challenge infection, mice were euthanized to collect spleen cell samples. For cell phenotype analysis, cells from spleen $(n=5)$ were stained with fluorophore-labeled surface markers. Anti-mouse CD16/32 (clone 2.4G2, BD Pharmingen, San Diego, California, USA) was used as Fc receptor blocker. Afterwards, antibody cocktails which contained anti-mouse CD23-FITC (clone 53-6.7, BD Pharmingen) and anti-mouse IgM-PerCP-Cy ${ }^{\text {TM }} 5.5$ (clone R6-60.2, BD Pharmingen) were used to treat cells. The stained cells washed after incubation, acquired by flow cytometer LSRFortessa (BD Biosciences, San Diego, California, USA) and analyzed using FlowJo program (Tree Star Inc., San Carlos, California, USA).

\section{Eosinophil counts}

Whole blood was collected from mice at week 1, 2, and 4 after primary infection and week 1, 2, and 4 after challenge infection. Whole blood was stained with Discombe's solution. A 20- $\mu \mathrm{l}$ of individual blood was immediately added into $180 \mu \mathrm{l}$ of Discombe's solution ( 5 vol. acetone, 5 vol. $1 \%$ aqueous eosin solution, 90 vol. distill water) and mixed well. Eosinophils in whole blood were counted under microscopy using a hemocytometer.

\section{Statistics}

All parameters were recorded for individuals within groups. Data were compared using analysis of variance and the nonparametric 1-way Kruskal-Wallis test in the PC-SAS system (SAS Institute, Cary, North Carolina, USA).

\section{RESULTS}

\section{Antibody responses in immune serum}

The time points for primary infection, reinfection, and sacrifice were seen in experimental schedules (Fig. 1A). Mouse sera collected at different time points were used to measure the levels of T. spiralis-specific antibody responses. The levels of total $\operatorname{IgG}$ in the serum specific T. spiralis ES Ag after primary infection and reinfection were determined (Fig. 1B). Total IgG antibody responses from mice primarily infected with $10 \mathrm{~T}$. spiralis (10 TS) showed significantly higher titers after reinfection (10100 TS) compared to those after primary infection (10 TS) $\left({ }^{*} P<0.05\right.$, Fig. $\left.1 \mathrm{~B}\right)$. With higher dose of primary infections (100 TS), no significant difference was found (Fig. 1B). These results indicated that mice primarily infected with 10 TS induced significantly higher levels of T. spiralis-specific antibodies upon reinfection.

\section{Antibody secreting cell responses}

During B cell differentiation and development, a fraction of germinal center B cells traffics to the bone marrow or spleen and develops into antibody secreting plasma cells (APC). To investigate the induction of antibody secreting cells, spleen cells were harvested at week 4 after challenge infection and stimulated in vitro with T. spiralis ES Ag (Fig. 2). Mice with 10100 TS showed higher levels of IgG antibodies bound to the $T$. spiralis ES Ag $\left({ }^{*} P<0.05\right)$. Overall, low dose infection (10 TS) induced increased antibody secreting cell responses after reinfection, consistent with the results of IgG antibody responses in sera.

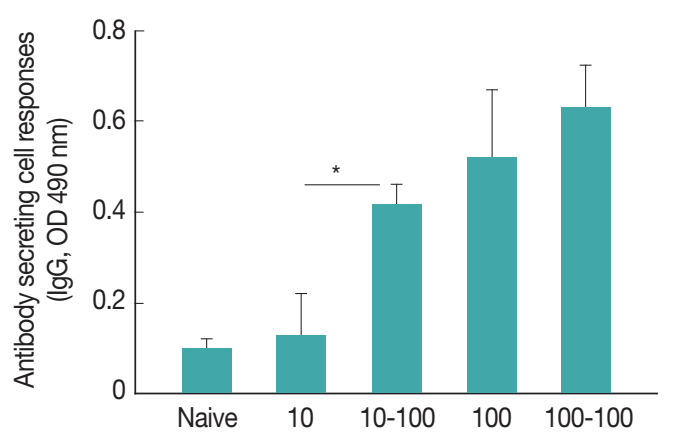

Fig. 2. Antibody secreting cell responses. Mouse spleen cells were prepared at week 4 post-challenge, added to a 96-well culture plate coated with $T$. spiralis ES antigen. At day 4, T. spiralisspecific $\lg G$ antibody was determined by using horseradish peroxidase (HRP)-conjugated secondary goat-anti-mouse antibodies. A significantly higher level of antibody secreting cell response was found between 10 TS and 10-100 TS $\left({ }^{*} P<0.05\right)$. 


\section{Resistance against reinfection}

The worm burden following challenge infection is the most important indicator to assess protective immunity. Mice were reinfected with 100 larvae of T. spiralis at week 4 after primary infection and worm burdens at day 7 and week 4 post-challenge were determined. As shown in Fig. $3 \mathrm{~A}$ and $3 \mathrm{~B}$, significantly decreased worm burdens were detected in mice primarily infected with 10 TS compared to primary controls (Fig. 3A,
$\left.\mathrm{B},{ }^{*} \mathrm{P}<0.05\right)$. However, no significant worm burden decrease was detected in mice primarily infected with 100 TS. These results indicated that mice primarily infected with 10 TS can effectively inhibit $T$. spiralis replication, whereas mice primarily infected with 100 TS cannot inhibit T. spiralis replication, indicating that different does of $T$. spiralis in mice induces different levels of resistance.

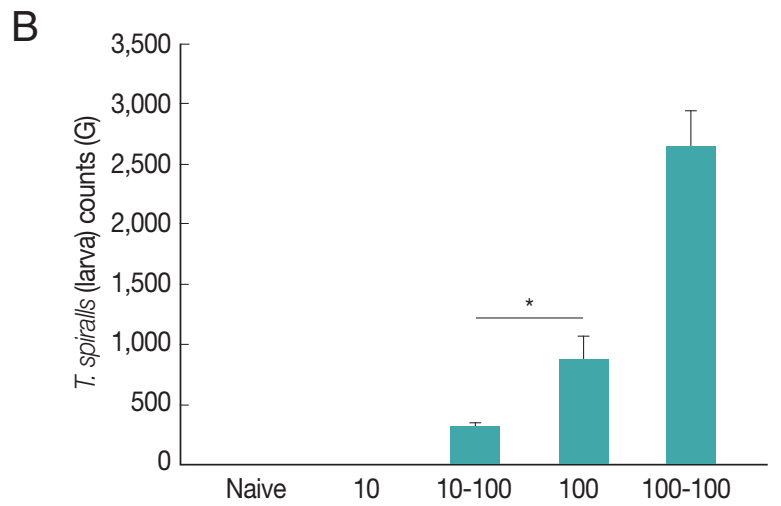

Fig. 3. Resistance to T. spiralis reinfection. Mice were primarily infected with 10 (10 TS) or 100 (100 TS) larvae of T. spiralis and after 4 weeks, mice were challenge infected with 100 larvae of T. spiralis to primarily infected mice (10-100 TS or 100-100 TS). At week 4 postchallenge, mice were sacrificed. The experiment was repeated 3 times. Worm burdens from mouse intestine and diaphragm were collected and counted $\left(\mathrm{A}, \mathrm{B},{ }^{\star} P<0.05\right)$.

A

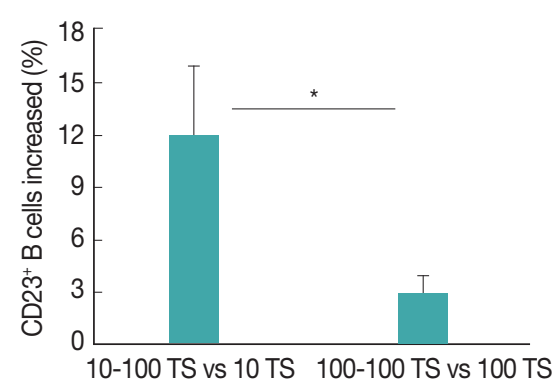

C
B

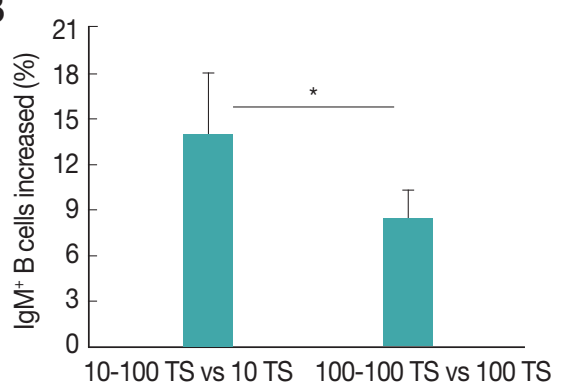

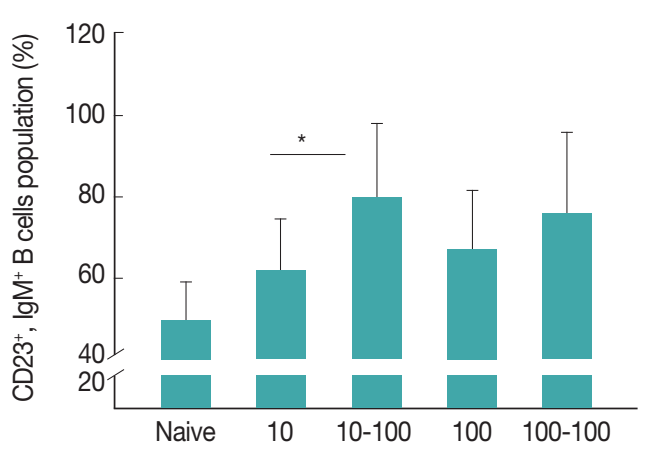

Fig. 4. $B$ cell responses. $C D 23^{+} B$ cells $\left(A,{ }^{*} P<0.05\right)$ and $\lg M^{+} B$ cell $\left(B,{ }^{*} P<0.05\right)$ responses were determined at week 4 after primary infection and post-challenge. Significant increases of $C D 23^{+} B$ cells and $\operatorname{lgM}^{+} B$ cell responses $\left(C,{ }^{*} P<0.05\right)$ were found in mice with $10-$ 100 TS compared to that with 10 TS. 


\section{B cell responses}

The populations of $\mathrm{CD} 23^{+} \mathrm{B}$ cells and $\mathrm{IgM}^{+} \mathrm{B}$ cells in spleen were measured as shown in Fig. 4. Mice were primarily infected with 10 TS or 100 TS, then challenge infected with 100 TS. Upon challenge infection, mice with a low dose of infection (10 TS) showed significant increases of $\mathrm{CD}_{23}{ }^{+}$and $\mathrm{IgM}^{+} \mathrm{B}$ cells, respectively, compared to mice with 100 TS infection $\left({ }^{*} P<0.05\right.$, Fig. 4A, B). Importantly, a higher level of double positive $\mathrm{CD}^{2} 3^{+} \mathrm{IgM}^{+} \mathrm{B}$ cells was only seen in mice with 10-100 TS infection, not in mice with 100-100 TS (Fig. 4C), indicating double positive $\mathrm{CD} 23^{+} \mathrm{IgM}^{+} \mathrm{B}$ cells might contribute the resistance induced by a light infection.

\section{Eosinophil profiles after primary infection and reinfection}

Whole bloods were collected as indicated in methods section and stained with Discombe's solution. As shown in Fig. 5, eosinophils raised significantly at week 2 after primary infection with both 10 TS and 100 TS (Fig. $5 \mathrm{~A}, \mathrm{~B},{ }^{*} P<0.01$ ). Slightly increased eosinophil level was observed at week 4 , which subsequently decreased in the following weeks. Upon challenge infection, eosinophils levels rose again at week 1 after challenge, reached its highest levels at week 2 , and then decreased at week 4 (Fig. 5A, B). Nonetheless, the challenge infection eosinophil count far exceeded those of primary infection eosinophil count at week 6 in 10 TS mice (Fig. 5A; ${ }^{* * *} P<0.05$ ). Interestingly, at week 8, 10 TS showed significantly higher numbers of eosinophil counts upon reinfection, whereas no significant increase of eosinophil was detected in the case of 100 TS mice (Fig. $5 \mathrm{~A}, \mathrm{~B} ;{ }^{* *} \mathrm{P}<0.01$ ), indicating that the eosinophils from 10 TS may contribute to the resistance induced by 10 TS primary

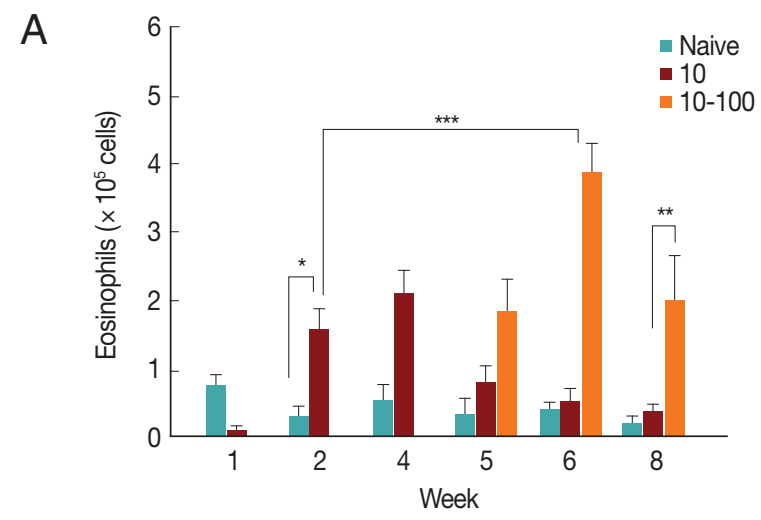

infection. The results indicated that significantly increased eosinophils at weeks 2 and 4 post-reinfection from 10 TS primary infection are protective.

\section{DISCUSSION}

In this study, we assessed the resistance of mice against $T$. spiralis reinfection by determining the larval worm burden reductions in the intestines for adults and in the diaphragms for larvae. Our results indicated that a dose of 10 TS infection induced significant resistance against reinfection, which correlated with IgG antibody response, CD23+ B cells, IgM+ $\mathrm{B}$ cells, and eosinophil responses. To our knowledge, this is the first report to identify the immune correlates of resistance to $T$. spiralis reinfection induced by a low dose of $T$. spiralis primary infection.

The dose of T. spiralis larvae used for the primary infection seems critical for developing parasitic resistance. In our study, only mice primarily infected with $10 \mathrm{TS}$ showed enhanced $\mathrm{T}$. spiralis-specific IgG antibody responses upon challenge. Because antibody response is dose-dependent as described by previous studies [5], observing a higher serum IgG level from 100 TS primary infection than 10 TS was reasonable. Yet, challenge infection with 10 TS mice with 100 TS increased the serum IgG level nearly 2 -fold by week 8 , whereas no significant enhancement was observed in 100-100 TS mice (Fig. 1B). A similar pattern was observed for antibody secreting cell responses as well, and combining these results, it can be assumed that these antibody responses may have led the host to acquire parasitic resistance.

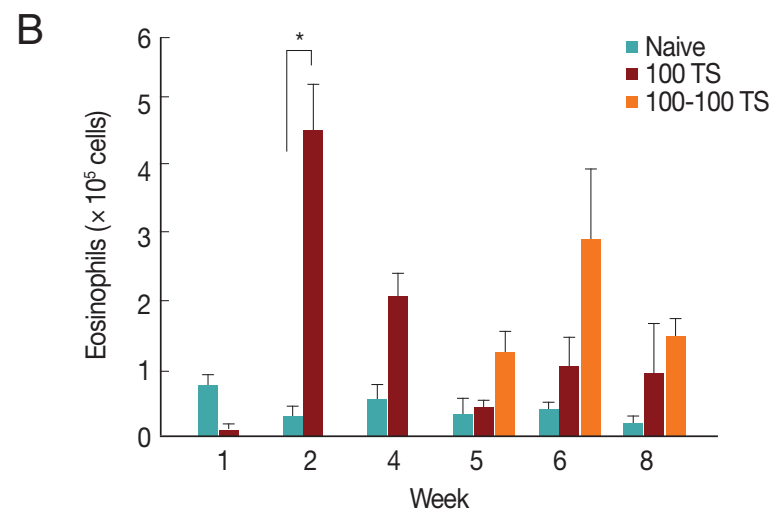

Fig. 5. Eosinophil responses. Eosinophils were counted from blood samples of mice at week 1, 2, 4 after primary and challenge infections. Eosinophils raised significantly at week 2 after primary infection with both 10 TS and 100 TS (Fig. 5A, B, ${ }^{*} P<0.01$ ). Following challenge infection, significantly higher level of eosinophil level was observed in 10 TS mice compared to primary infection (A, $\left.{ }^{\star \star} P<0.01\right)$, whereas no significant increase of eosinophil was detected in the case of 100 TS mice (B). 
Repeated exposures and treatment of Schistosoma mansoni have been documented to eventually lead to higher levels of resistance towards the parasite [26], and the same can be applicable to our study. With dramatic worm burden difference between mice with 10-100 TS and 100 TS (Fig. 3A, B), it is highly plausible that a previous exposure to 10 TS have resulted in a greater resistance to reinfection. Results from our study showed that significantly high levels of eosinophils were detected at week 2 and 4 after primary infection and reinfection. At week 4 post-reinfection, mice primarily infected with a low dose of T. spiralis (10 TS) showed a higher number of eosinophils compared to those with 100 TS (Fig. 5A, B), indicating that eosinophils are required in developing resistance towards T. spiralis reinfection [19].

In addition to eosinophils, we found that the resistance to reinfection correlated with elevated $T$. spiralis-specific antibody response, $\mathrm{CD}_{23}{ }^{+} \mathrm{B}$ cells and $\mathrm{IgM}^{+} \mathrm{B}$ cells responses, indicating eosinophils are involved in the resistance to reinfection by binding themselves to larvae in the presences of antibodies [19]. Humoral memory is maintained by memory B cells and plasma cells. Reinfection triggers the formation of antibodyforming cells (AFC) [21]. In our study, significantly higher levels of antibody secreting cells were found in mice with 10-100 TS (Fig. 2), indicating memory B cells differentiated into plasma cells and produced antibodies upon reinfection. $\mathrm{CD}_{23}{ }^{+} \mathrm{B}$ cells are reported to be correlated with the development of resistance to S. mansoni reinfection and eosinophils [20], which is consistent with our results. IgG1 memory B cell has been taken as a surrogate marker for memory in the mouse [21]. However, a recent study revealed the existence of a long-lived IgM memory B cell population in mouse in addition to classical IgG+ cells [21]. This study is consistent with our results as significantly raised $\mathrm{IgM}^{+} \mathrm{B}$ cell response was observed upon reinfection, which may indicate that $\operatorname{IgM}^{+} \mathrm{B}$ cells might contribute to resistance.

Memory B cells and parasite-specific antibody are critical for development of parasitic resistance. A study on Trichuris muris has shown that $B$ cells are a requirement for parasite resistance [27], and mitigating parasitic invasion through antigen-specific antibody towards T. spiralis has been confirmed in vitro $[28,29]$. Furthermore, parasite-specific antibodies and its associated Th2 responses limit worm establishment and may even play a role in diminishing the effect of challenge infections [27]. Similarly, splenic antibody response towards Haemonchus contortus reveals that resistance mounted towards the parasite in sheep is reliant on Th2 type immune response [30]. However, these previous studies largely focused on primary infections, and the correlations of immune response profiles with the resistance against reinfection have not been clarified.

In conclusion, our study has provided new insight into resistance induced by a low dose (10 TS) of T. spiralis. In the present study, we have demonstrated that upon reinfection, mice primarily infected with $10 \mathrm{TS}$ induced enhanced IgG antibody, CD23+ B cells, IgM B cells, and eosinophil responses, resulting in significant reduction of T. spiralis burden, thereby indicating that all of these factors are correlated with the resistance against reinfection by $T$. spiralis.

\section{ACKNOWLEDGMENTS}

This work was supported by a grant from the National Research Foundation of Korea (NRF) (NRF-2014R1A2A 2A01004899) and a grant from the Ministry of Health \& Welfare, Republic of Korea (HI15C2928).

\section{CONFLICT OF INTEREST}

The authors have no conflicts of interest to declare.

\section{REFERENCES}

1. Kim G, Choi MH, Kim JH, Kang YM, Jeon HJ, Jung Y, Lee MJ, Oh MD. An outbreak of trichinellosis with detection of Trichinella larvae in leftover wild boar meat. J Korean Med Sci 2011; 26: 1630-1633.

2. Gottstein B, Pozio E, Nockler K. Epidemiology, diagnosis, treatment, and control of trichinellosis. Clin Microbiol Rev 2009; 22: 127-145

3. Kolodziej-Sobocinska M, Dvoroznakova E, Dziemian E, Machnicka-Rowinska B. Trichinella spiralis reinfection: macrophage activity in BALB/c mice. Parasitol Res 2007; 101: 629-637.

4. Grove DI, Hamburger J, Warren KS. Kinetics of immunological responses, resistance to reinfection, and pathological reactions to infection with Trichinella spiralis. J Infect Dis 1977; 136: 562570.

5. Franssen FF, Fonville M, Takumi K, Vallee I, Grasset A, Koedam MA, Wester PW, Boireau P, van der Giessen JW. Antibody response against Trichinella spiralis in experimentally infected rats is dose dependent. Vet Res 2011; 42: 113.

6. Smith HJ, Snowdon KE, Finley GG, Laflamme LF. Pathogenesis and serodiagnosis of experimental Trichinella spiralis spiralis and Trichinella spiralis nativa infections in cattle. Can J Vet Res 1990; 54: 355-359. 
7. Tomasovicova O, Corba J, Havasiova K, Rybos M, Stefancikova A. Experimental Trichinella spiralis infection in sheep. Vet Parasitol 1991; 40: 119-126.

8. Pajersky A, Tomasovicova O, Kincekova J, Zubricky P, Koren J. Susceptibility and reactivity of sheep to Trichinella spiralis infection. Vet Med (Praha) 1996; 41: 233-240.

9. Reina D, Munoz-Ojeda MC, Serrano F, Molina JM, Navarrete I. Experimental trichinellosis in goats. Vet Parasitol 1996; 62: 125132.

10. Korinkova K, Pavlickova Z, Kovarcik K, Koudela B. Distribution of muscle larvae and antibody dynamics in goats experimentally infected with Trichinella spiralis. Parasitol Res 2006; 99: 643-647.

11. Smith HJ, Snowdon KE. Experimental Trichinella infections in ponies. Can J Vet Res 1987; 51: 415-416.

12. Soule C, Dupouy-Camet J, Georges P, Fontaine JJ, Ancelle T, Delvigne $\mathrm{A}$, Perret $\mathrm{C}$, Collobert $\mathrm{C}$. Biological and parasitic variations in horses infested and reinfested by Trichinella spiralis. Vet Res 1993; 24: 21-31.

13. Pozio E, Sofronic-Milosavljevic L, Gomez Morales MA, Boireau P, Nockler K. Evaluation of ELISA and western blot analysis using three antigens to detect anti-Trichinella IgG in horses. Vet Parasitol 2002; 108: 163-178.

14. Moller LN, Petersen E, Gamble HR, Kapel CM. Comparison of two antigens for demonstration of Trichinella spp. antibodies in blood and muscle fluid of foxes, pigs and wild boars. Vet Parasitol 2005; 132: 81-84.

15. Nockler K, Serrano FJ, Boireau P, Kapel CM, Pozio E. Experimental studies in pigs on Trichinella detection in different diagnostic matrices. Vet Parasitol 2005; 132: 85-90.

16. Korinkova K, Kovarcik K, Pavlickova Z, Svoboda M, Koudela B. Serological detection of Trichinella spiralis in swine by ELISA (enzyme-linked immunosorbent assay) using an excretory-secretory (E/S) antigen. Parasitol Res 2008; 102: 1317-1320.

17. Dvoroznakova E, Kolodziej-Sobocinska M, Hurnikova Z. Trichinella spiralis reinfection: Changes in cellular and humoral immune response in BALB/c mice. Helminthologia 2012; 49: 201210.

18. Dvoroznakova E, Jalcova M, Hurnikova Z. Differences in cellular immune responses of mice BALB/c to low and high infective doses of Trichinella spiralis. Helminthologia 2013; 50: 244-253.

19. Huang L, Gebreselassie NG, Gagliardo LF, Ruyechan MC, Luber KL, Lee NA, Lee JJ, Appleton JA. Eosinophils mediate protective immunity against secondary nematode infection. J Immunol 2015; 194: 283-290.

20. Mwinzi PN, Ganley-Leal L, Black CL, Secor WE, Karanja DM, Colley DG. Circulating CD $23^{+}$B cell subset correlates with the development of resistance to Schistosoma mansoni reinfection in occupationally exposed adults who have undergone multiple treatments. J Infect Dis 2009; 199: 272-279.

21. Reynaud CA, Descatoire M, Dogan I, Huetz F, Weller S, Weill JC. IgM memory B cells: A mouse/human paradox. Cell Mol Life Sci 2012; 69: 1625-1634.

22. Sohn WM, Huh S, Chung DI, Pozio E. Molecular identification of Korean Trichinella isolates. Korean J Parasitol 2003; 41: 125127.

23. Quan FS, Matsumoto T, Shin YO, Min YK, Yang HM, Othman T, Lee JB. Relationships between IgG, IgM, IgE and resistance to reinfection during the early phase of infection with Clonorchis sinensis in rats. Immunol Invest 2004; 33: 51-60.

24. Robinson K, Bellaby T, Wakelin D. Immunity to Trichinella spiralis transferred by serum from vaccinated mice not protected by immunization. Parasite Immunol 1995; 17: 85-90.

25. Quan FS, Vunnava A, Compans RW, Kang SM. Virus-like particle vaccine protects against 2009 H1N1 pandemic influenza virus in mice. PLoS One 2010; 5: e9161.

26. Karanja DM, Hightower AW, Colley DG, Mwinzi PN, Galil K, Andove J, Secor WE. Resistance to reinfection with Schistosoma mansoni in occupationally exposed adults and effect of HIV-1 coinfection on susceptibility to schistosomiasis: A longitudinal study. Lancet 2002; 360: 592-596.

27. Blackwell NM, Else KJ. B cells and antibodies are required for resistance to the parasitic gastrointestinal nematode Trichuris muris. Infect Immun 2001; 69: 3860-3868.

28. McVay CS, Tsung A, Appleton J. Participation of parasite surface glycoproteins in antibody-mediated protection of epithelial cells against Trichinella spiralis. Infect Immun 1998; 66: 1941-1945.

29. McVay CS, Bracken P, Gagliardo LF, Appleton J. Antibodies to tyvelose exhibit multiple modes of interference with the epithelial niche of Trichinella spiralis. Infect Immun 2000; 68: 19121918.

30. Alba-Hurtado F, Munoz-Guzman MA. Immune responses associated with resistance to haemonchosis in sheep. Biomed Res Int 2013; 2013: 162158. 
